\title{
SURGICAL TREATMENT OF GASTROESOPHAGEAL REFLUX DISEASE: total or partial fundoplication? Systematic review and meta-analysis
}

\author{
Rodrigo F. RAMOS1, Suzana Angélica S. LUSTOSA², Carlos Augusto P. de ALMEIDA², \\ Carolina P. da SILVA ${ }^{3}$ and Delcio MATOS ${ }^{4}$
}

\begin{abstract}
Context - Although the high incidence of gastroesophageal reflux disease (GERD) in the population, there is much controversy in this topic, especially in the surgical treatment. The decision to use of a total or partial fundoplication in the treatment of GERD is still a challenge to many surgeons because the few evidence found in the literature. Objective - To bring more clear evidence in the comparison between total and partial fundoplication. Data sources - A systematic review of the literature and metaanalysis with randomized controlled trials accessed from MEDLINE, LILACS, Cochrane Controlled Trials Database was done. The outcomes remarked were: dysphagia, inability to belch, bloating, recurrence of acid reflux, heartburn and esophagitis. For data analysis the odds ratio was used with corresponding $95 \%$ confidence interval. Statistical heterogeneity in the results of the metaanalysis was assessed by calculating a test of heterogeneity. The software Review Manager 5 (Cochrane Collaboration) was utilized for the data gathered and the statistical analysis. Sensitive analysis was applied using only trials that included follow-up over 2 years. Results - Ten trials were included with 1003 patients: 502 to total fundoplication group and 501 to partial fundoplication group. The outcomes dysphagia and inability to belch had statistical significant difference $(P=0.00001)$ in favor of partial fundoplication. There was not statistical difference in outcomes related with treatment failure. There were no heterogeneity in the outcomes dysphagia and recurrence of the acid reflux. Conclusion - The partial fundoplication has lower incidence of obstructive side effects.
\end{abstract}

HEADINGS - Gastroesophageal reflux, surgery. Fundoplication. Review. Meta-analysis.

\section{INTRODUCTION}

The gastroesophageal reflux disease (GERD) is one of the diseases that have the strongest impact in the society nowadays. It is responsible for the major costs in the treatment of the gastrointestinal diseases in $\mathrm{USA}^{(29)}$ with low scores of quality of life $^{(9,27)}$.

In the mild cases of GERD, the clinical management is most indicated; however, the surgical treatment is a good option in severe forms and in young patients who do not want to take tablets for the rest of their lives.

In 1956, Rudolf Nissen ${ }^{(25)}$ first described the $360^{\circ}$ fundoplication, believing that this procedure increases the pressure in the lower esophageal sphincter. Until nowadays, this is the most performed surgical treatment in GERD, because the good long-term results in the control of the acid reflux. However, are related high levels of post-operative dysphagia in these patients ${ }^{(35)}$.
An alternative for the total fundoplication was the creation of partial fundoplications. Toupet in $1963^{(34)}$, created a posterior partial fundoplication with $180^{\circ}$ circumference. After him, other surgeons created many others partial fundoplications looking to reduce the post-operative dysphagia ${ }^{(19)}$, but the long-term results showed a rate of recurrence of the reflux higher than the Nissen procedure ${ }^{(17)}$.

Many studies comparing total and partial fundoplications started to appear in the literature, but most of them failed to show a significant difference ${ }^{24,38)}$. Recently, a meta-analysis was published showing that both procedures have a good control of the reflux, but with low incidence of dysphagia in the partial fundoplication group, however, the methodological quality of the included studies was very poor ${ }^{(35)}$.

The aim of this study is to bring a more clear evidence for this question, through a systematic review and meta-analysis, with a rigorous methodological quality assessment.

\footnotetext{
Research performed at the Cochrane Center of São Paulo and Gastrosurgery Post-graduation Program, Universidade Federal de São Paulo, Escola Paulista de Medicina, São Paulo, SP, Brasil.

Conflict of Interest Disclosure: The authors undersigned also certify that we have no commercial associations that might pose a conflict of interest in connection with the submitted article.

${ }^{1}$ Departamento de Cirurgia, Universidade Federal Fluminense, Niterói, RJ; ${ }^{2}$ Unidade de Ensino, Pesquisa e Extensão, Hospital Munir Rafful, Volta Redonda, RJ; ${ }^{3}$ Faculdade de Medicina de Volta Redonda, RJ; ${ }^{4}$ Programa da Pós-graduação em Gastrocirurgia, Universidade Federal de São Paulo, SP, Brasil

Correspondence: Dr. Rodrigo Felippe Ramos - Rua Napoleão de Barros, 610 - Vila Clementino - 04024-002 - São Paulo, SP, Brasil. E-mail: rofelippe@terra.com.br
} 


\section{METHODS}

This systematic review and meta-analysis was performed in the Gastro-surgery post-graduation program of the Universidade Federal de São Paulo, Cochrane Center of Brazil, and Researching, Learning and Extension Unity of Hospital Munir Rafful, Volta Redonda, RJ, Brazil and had approval by the Ethics Research Committee of this institution. The research followed the recommendations of the Cochrane Collaboration and the methodological quality was evaluated by the QUORUM statement check-list.

The search strategy was performed following the recommendation of the Cochrane Handbook for Systematic Reviews of Interventions version 5.0.1., in the MEDLINE, LILACS and the Cochrane Collaboration Trials Register (CCTR) electronic databases; annals of congresses, banks of thesis and references of the primary studies. The following Medical Subject Heading (MeSH) and/or text words were used: "gastroesophageal reflux", "fundoplication", "Nissen", "partial"; associated with the Cochrane highly sensitive search strategy for $\mathrm{RCTs}^{(40)}$ (Figure 1).

\begin{tabular}{|ll|}
\hline $\mathbf{N}^{\mathbf{o}}$ & \multicolumn{1}{c|}{ Terms and combinations utilized } \\
\hline$\# 1$ & Cochrane highly sensitive search strategy for RCTs \\
$\# 2$ & MH gastroesophageal reflux or Tw gastroesophageal reflux or Ti \\
& gastroesophageal reflux \\
$\# 3$ & Fundoplication or Nissen or partial \\
$\# 4$ & $\# 2$ and \#3 \\
$\# 5$ & $\# 1$ and \#4 \\
\hline
\end{tabular}

FIGURE 1. Search strategy in electronic data basis RCTs = Randomized controlled trials; $\mathrm{MH}=$ Medical headings; $\mathrm{Tw}=$ Text words; $\mathrm{Ti}=$ English title

Only randomized clinical trials (RCT) were included, and their quality was measured by the CONSORT check-list and by a randomization classification (Figure 2). Only RCTs with "A" classification were included. Studies that contained children, patients with severe esophageal dismotility and other techniques that we can not classified as total or partial fundoplication were excluded. If a trial had subsequent publications of the same casuistic, we considerate the last analysis of each outcome in the follow-up.

\begin{tabular}{|ll|}
\hline \multicolumn{1}{|c|}{ Randomization classification } \\
\hline A & Correct randomization \\
B & Non-specified \\
C & Incorrect randomization \\
D & Non-randomized \\
\hline
\end{tabular}

FIGURE 2. Randomization classification (Cochrane Handbook for Systematic Reviews of Interventions version 5.0.1)

The following outcome parameters were analyzed: dysphagia, recurrence of acid reflux, bloating, inability to belch, esophagitis and heartburn. The outcomes dysphagia, bloating, inability to belch and heartburn were analyzed by validated scales in the primary studies. As well, we only consider the results of the outcomes esophagitis and recurrence of reflux when they were evaluated by endoscopic and $\mathrm{pHmetric}$ exams, respectively.

Data were collected from the selected studies and inserted in the Review Manager Software version 5. The statistical method used was the Mantel-Haenszel test, considering a $P$ value less than 0.05 statistically significant. Summary statistics were calculated using the odds ratio (OR) and associated 95\% confidence intervals $(\mathrm{CI})$ in the fixed model. Heterogeneity was tested using the Cochrane Chi-Square statistic and the degree of freedom to calculate the $\mathrm{I}^{2}$, and assumed to be present when $\mathrm{I}^{2}$ was less than $50 \%$. We also performed a subgroup analysis of the outcomes parameters dysphagia and recurrence of acid reflux in studies with follow-up higher than 2 years. Publication bias was tested using a funnel plot in the outcomes dysphagia and recurrence of acid reflux.

\section{RESULTS}

Seventeen RCTs were found with the search strategy (Figure $3)$. Three studies were excluded by exclusion criteria: one study in children ${ }^{(10)}$, one comparing Hill fundoplication ${ }^{(7)}$ and another that not include the principal outcomes studied ${ }^{(6)}$. Four studies were excluded by low methodological quality ${ }^{(14,18,33,36)}$. At the end, 10 RCTs were selected (Figure 4).

The partial fundoplication resulted in a less incidence of obstructive effects compared with the total fundoplication. There was a significant difference in post-operative dysphagia in favor of the partial fundoplication with $P$ value $<0.0001$ and $\mathrm{OR}=$ 0.46 with CI: $0.32-0.66$ (Figure 5). In the outcome inability to belch, we found similar results with $P<0.0001$ and $\mathrm{OR}=$ 0.47 with CI: $0.33-0.67$ (Figure 6). However, we did not found statistically difference in gas bloating, with a $P$ value $=0.18$ and $\mathrm{OR}=0.78$ with $\mathrm{CI}: 0.54-1.13$ (Figure 7).

In the outcomes related with treatment failure, we did not find any statistical difference between partial and total fundoplication. In the pooled results of the outcome recurrence of acid reflux, we found a $P$ value of 0.77 with OR $=1.10$ and CI: $0.59-2.05$ (Figure 8$)$. When we analyzed the outcome heartburn, we found a $P$ value of 0.34 with OR $=1.22$ with CI: 0.81-1.86 (Figure 9). The analysis of the outcome esophagitis results in a $P$ value of 0.74 with $\mathrm{OR}=1.12$ and CI: 0.56-2.25 (Figure 10).

In the subgroup analysis in studies with follow-up higher than 2 years, we found similar results as the overall analysis: the outcome disphagya results in a $P$ value of 0.03 with $\mathrm{OR}=0.56$ and CI: $0.33-0.95$ (Figure 11), and the outcome recurrent reflux shows a $P$ value of 0.39 with $\mathrm{OR}=0.76$ and CI: $0.42-1.41$ (Figure 12). We did not found significant heterogeneity in none of the pooled analysis of the outcomes.

We considerate the chance of publication bias in the outcome dysphagia because the heterogeneous distribution of the trials in the funnel-plot (Figure 13). In the outcome recurrence of acid reflux, we found a homogeneous distribution of the trials; however, we can not analyze the chance of bias because the few number of studies (Figure 14). 


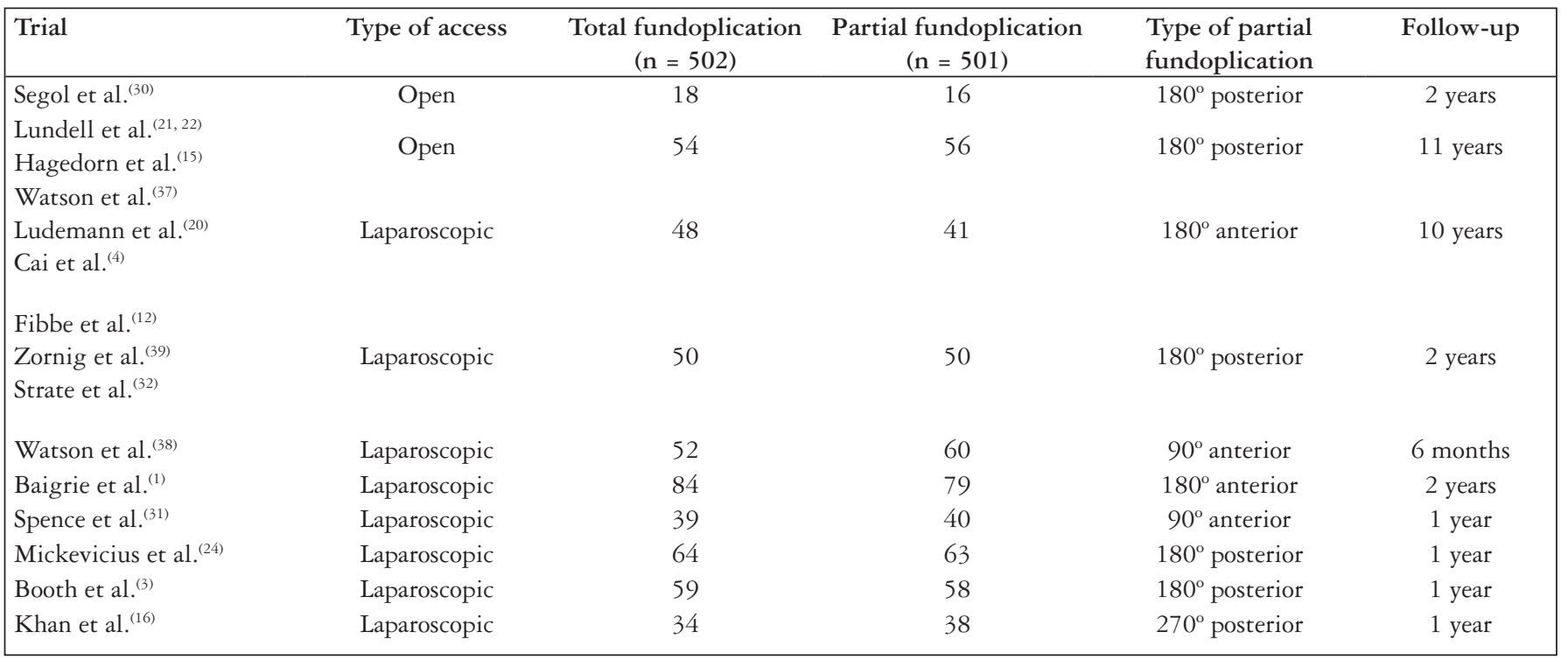

FIGURE 3. Included studies in the systematic review and their characteristics

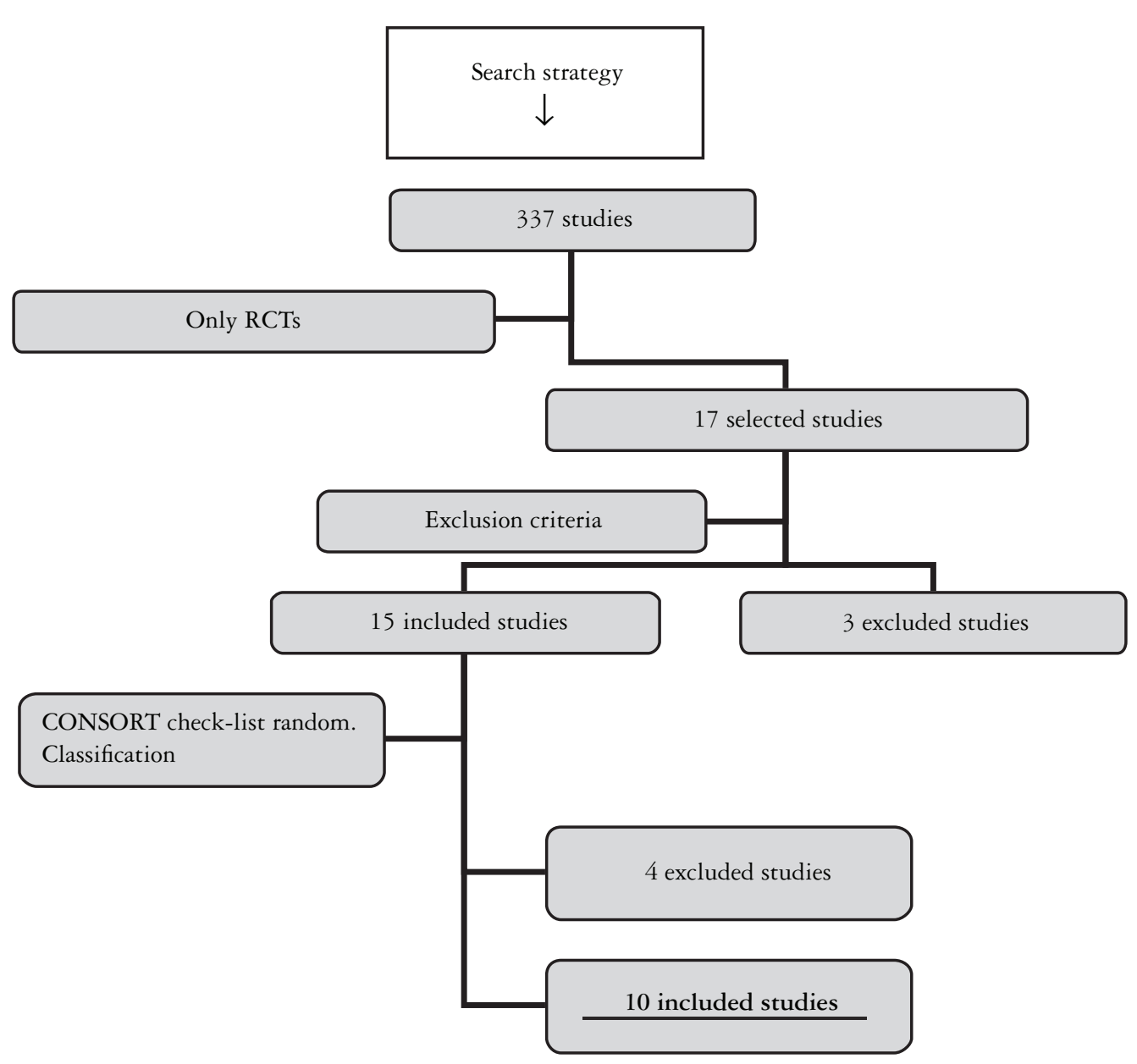

FIGURE 4. Study methodology diagram according with QUORUM statement checklist. RCT indicated randomized clinical trial 


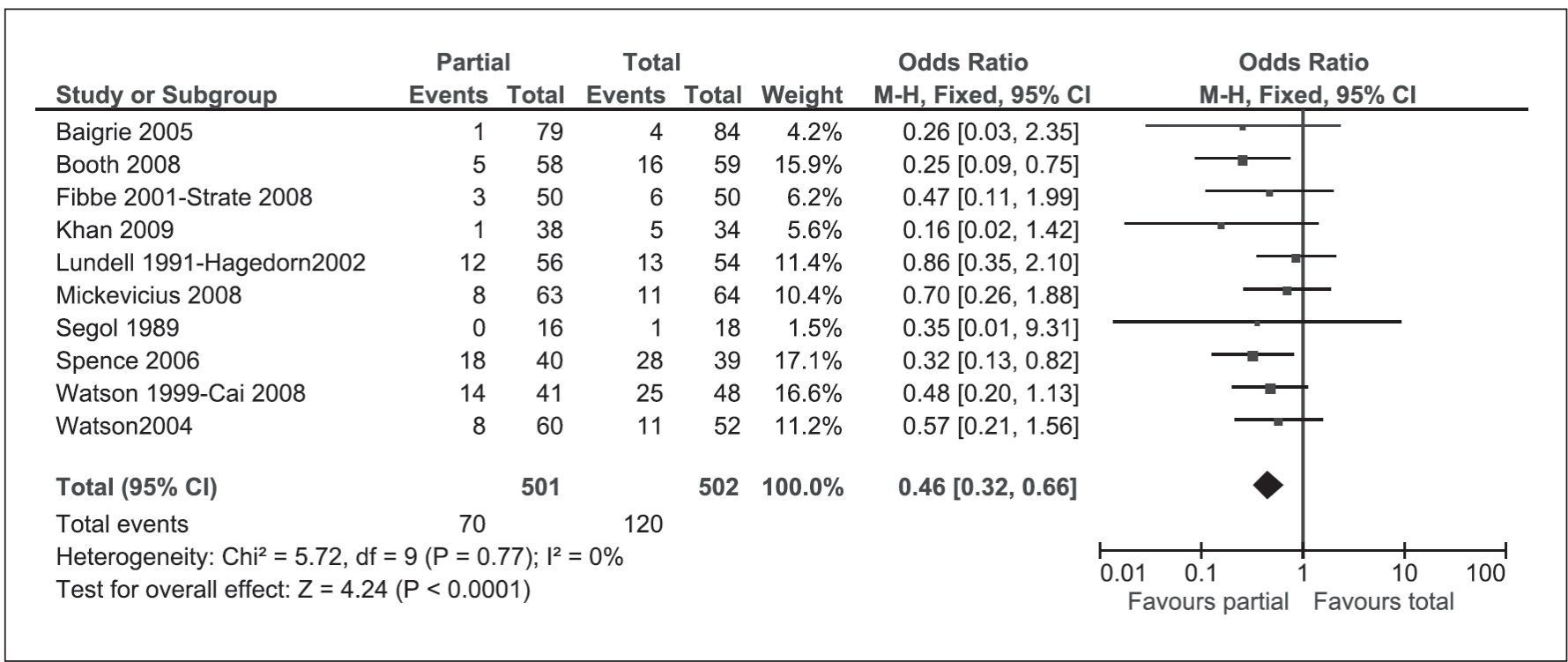

FIGURE 5. Graphic showing the meta-analysis of the 10 studies comparing partial and total fundoplications in GERD. Presentation of results of postoperative dysphagia, by OR, with CI of $95 \%$

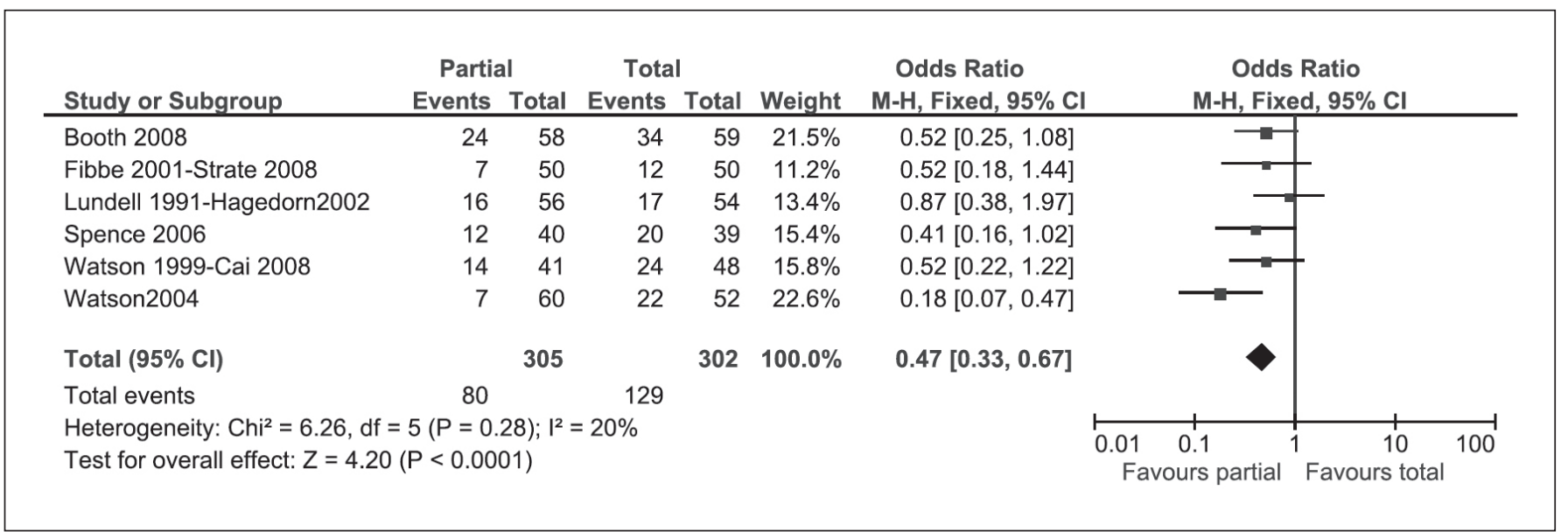

FIGURE 6. Graphic showing the meta-analysis of the six studies comparing partial and total fundoplications in GERD. Presentation of results of inability to belch, by OR, with CI of $95 \%$

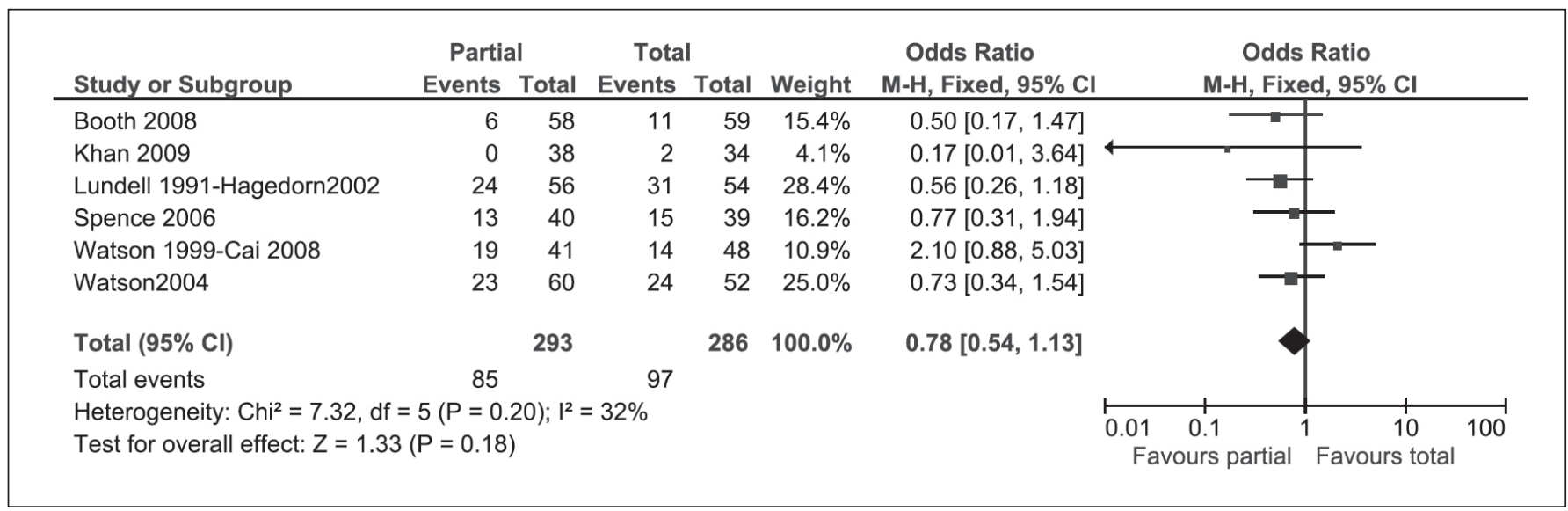

FIGURE 7. Graphic showing the meta-analysis of the six studies comparing partial and total fundoplications in GERD. Presentation of results of gas bloating, by OR, with CI of $95 \%$ 


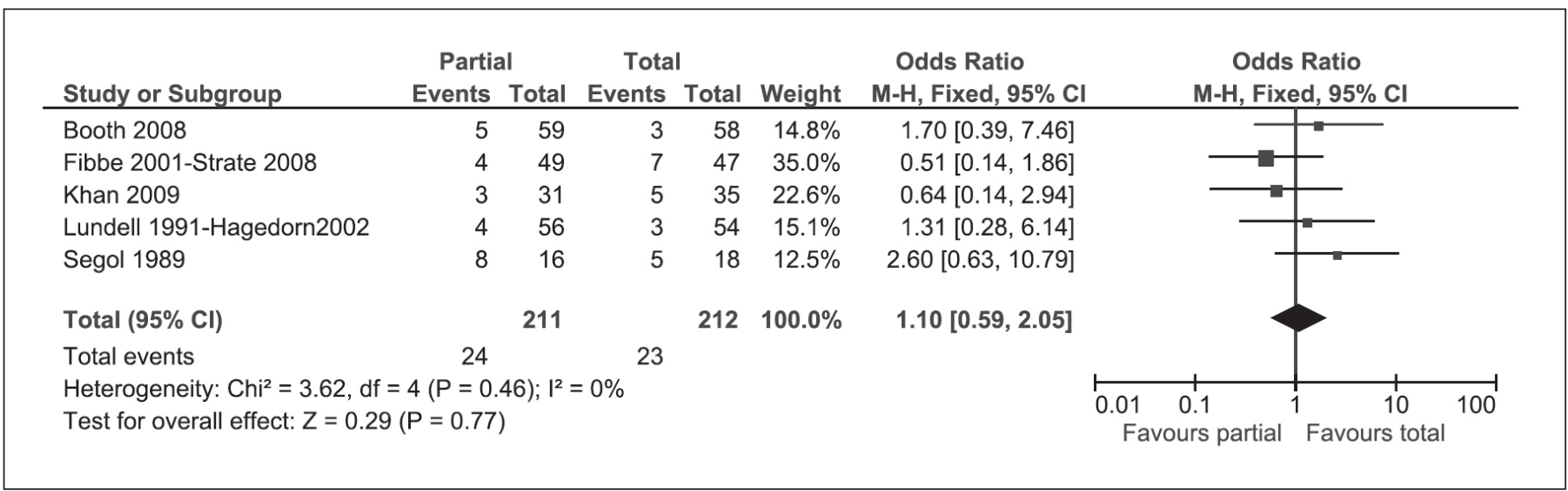

FIGURE 8. Graphic showing the meta-analysis of five studies comparing partial and total fundoplications in GERD. Presentation of results of recurrence of acid reflux, by OR, with CI of $95 \%$

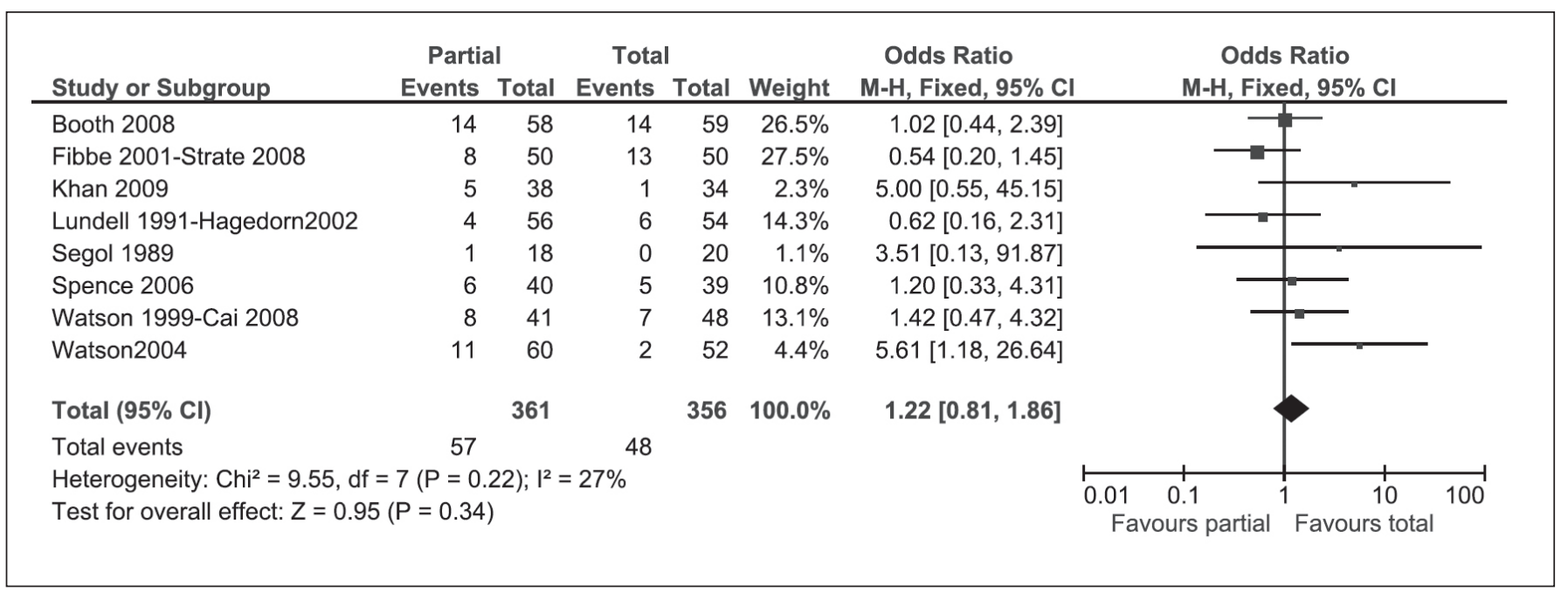

FIGURE 9. Graphic showing the meta-analysis of eight studies comparing partial and total fundoplications in GERD. Presentation of results of heartburn by OR, with CI of $95 \%$

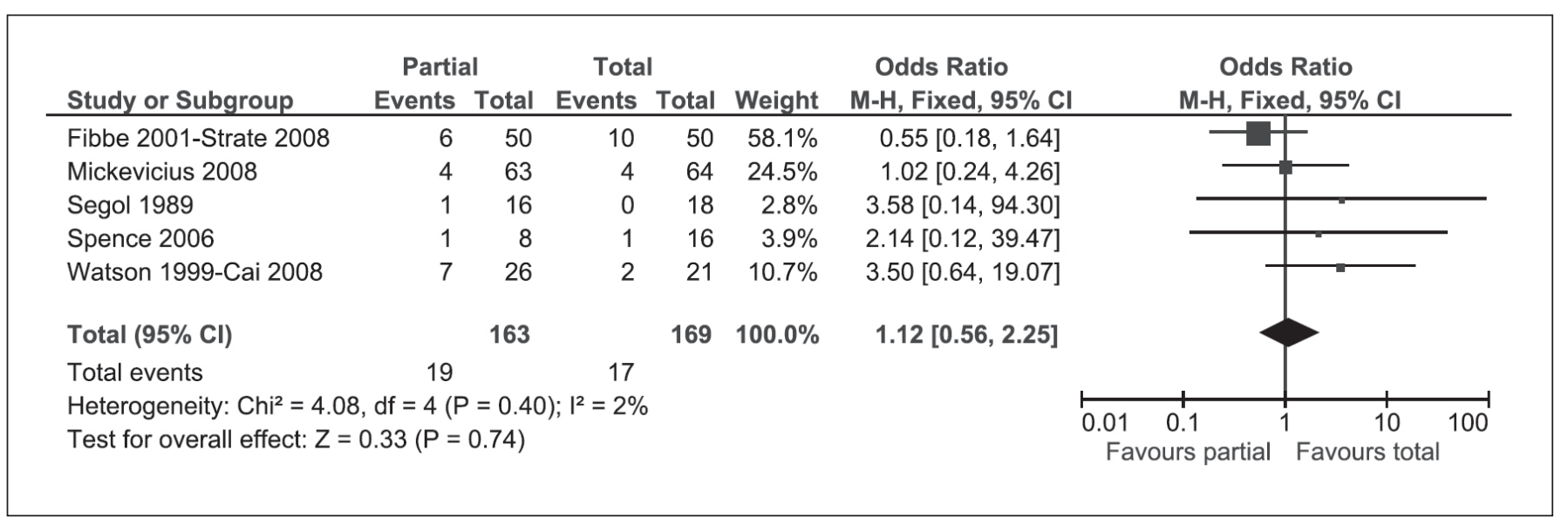

FIGURE 10. Graphic showing the meta-analysis of five studies comparing partial and total fundoplications in GERD. Presentation of results of esophagitis by OR, with CI of $95 \%$ 


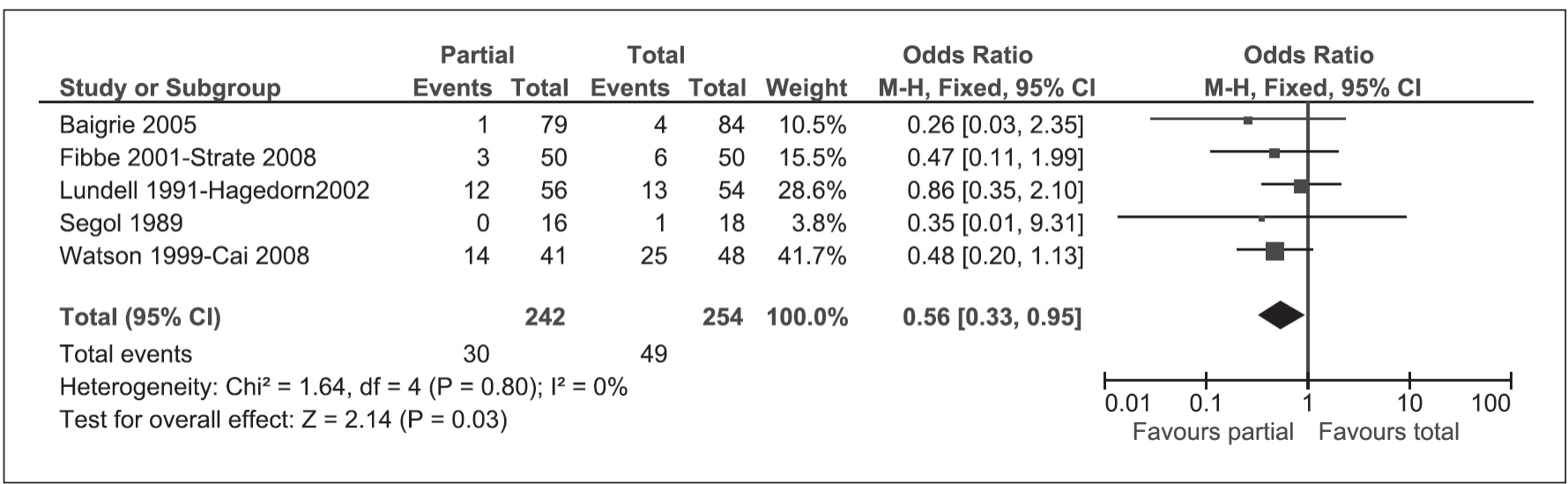

FIGURE 11. Graphic showing the meta-analysis of five studies comparing partial and total fundoplications with follow-up $>2$ years in GERD. Presentation of results of dysphagia by OR, with CI of $95 \%$

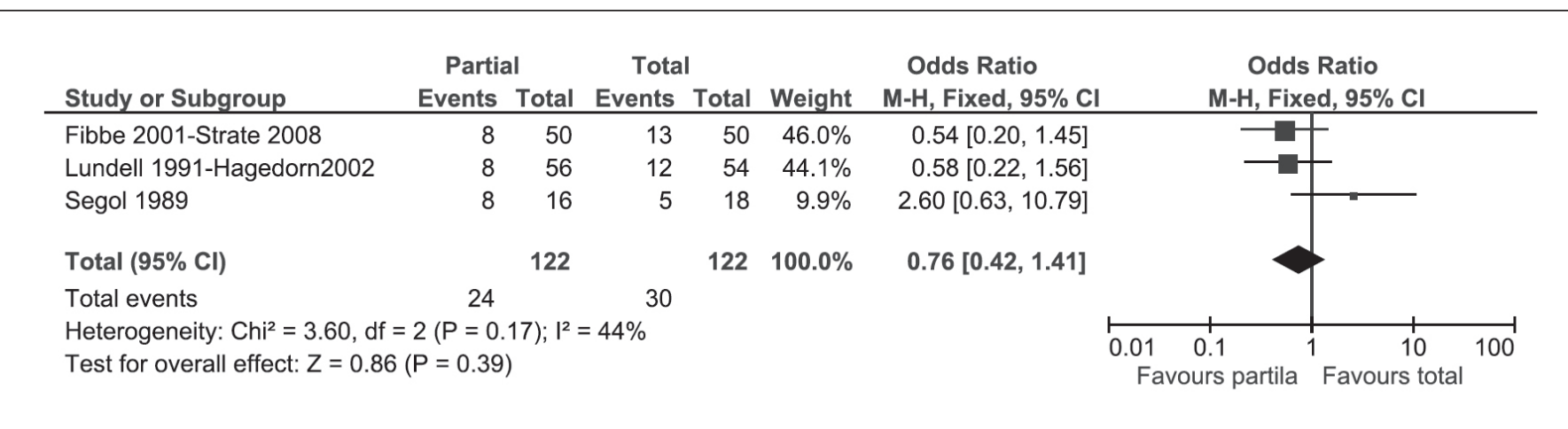

FIGURE 12. Graphic showing the meta-analysis of three studies comparing partial and total fundoplications with follow-up $>2$ years in GERD. Presentation of results of recurrence of acid reflux by OR, with CI $95 \%$

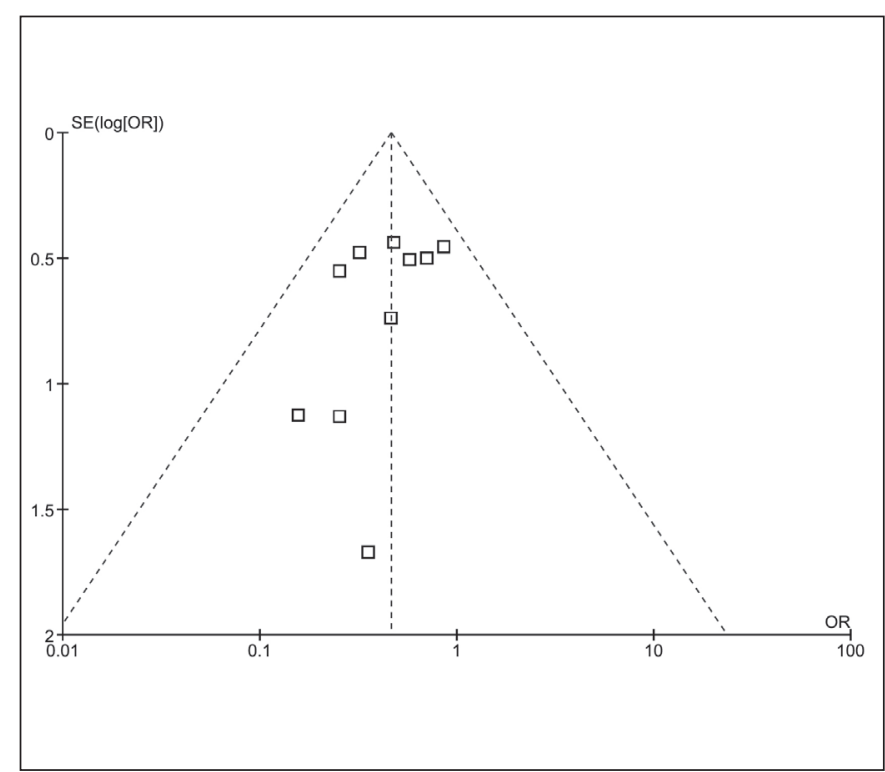

FIGURE 13. Funnel - plot graphic showing 10 studies comparing partial and total fundoplications in order to detect publication bias in the outcome dysphagia

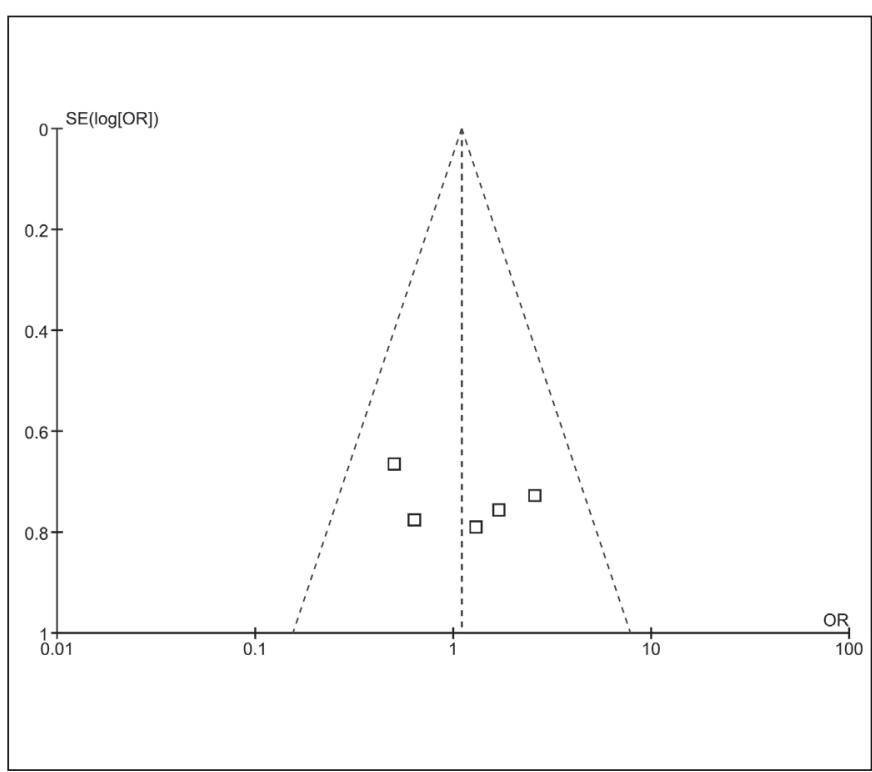

FIGURE 14. Funnel - plot graphic showing five studies comparing partial and total fundoplications in order to detect publication bias in the outcome recurrent reflux 


\section{DISCUSSION}

The anti-reflux surgery is the one of most controversial topics in gastroenterological surgery, especially in choice of total or partial fundoplications in GERD. In a few decades ago, this decision was made according to manometric finds in the pre-operative exam, believing that patients with abnormal esophageal motility had a higher chance to develop postoperative dysphagia ${ }^{(13)}$. However, subsequent randomized studies failed to confirm this hypothesis ${ }^{(28)}$.

The search for better evidence about this subject is growing along this decade. Catarci et al..$^{(5)}$, in a systematic review with meta-analysis, analyzed nine studies comparing total and partial fundoplications: six with open and three with laparoscopic access. They did not find any statistical difference between the groups in the outcomes dysphagia and recurrence of acid reflux. Recently, another systematic review with meta-analysis ${ }^{(35)}$ was published with 11 studies included. A lower incidence of obstructive effects as dysphagia was found with statistical difference, with no difference in treatment failure parameters.

Although the Varin et al. ${ }^{(35)}$ study followed the Cochrane Collaboration recommendations and used the QUORUM statement check-list, there are important considerations to make. As the Catarci et al. ${ }^{(5)}$ study, the methodological quality of the included studies was very poor, and most of these studies dated from the early of the 90 decade, when the laparoscopy was in the beginning. Other relevant points are the unclear outcome measures and statistical analysis, as detection of publication bias.

We believe that the path to find a more clear evidence of this subject is the adoption of a more rigorous methodology in the systematic review with meta-analysis. We decided to include only RCTs with adequate parameters of randomization, as sequence generation, allocation concealment and blinding. We also adopted explicit criteria of outcome measures. For example, many studies reported recurrence of acid reflux; however, most of them are not clear in the method to find this outcome. We decide only to include studies that measured this outcome by $\mathrm{pHmetric}$ exam, in order to standardize this analysis.

An interesting point that we observed in our metaanalysis is the fact that only two included studies show significant statistical difference in the outcome dysphagia ${ }^{(3,31)}$. However, when the meta-analysis is done, we found a high statistical difference in this outcome. Although the higher incidence of recurrent acid reflux in follow-up of partial fundoplications studies ${ }^{(2,17)}$, we did not find statistical difference in the RCTs and in the meta-analysis. These aspects show the importance of the systematic review and meta-analysis in find more accurate evidence. According to our results in the subgroup analysis with studies with follow-up longer than 2 years, both techniques have good control of the reflux in long-term. In our results, partial fundoplications have less dysphagia events than total fundoplication, however the meta-analysis "diamond" is closer the base line in the subgroup with longer followup than in the analysis with all 10 studies. It made us think the possibility to, having more studies with longer follow-up, the incidence of dysphagia were the same in both techniques. Maybe in a future actualization of this review, we will have the answer.

Some authors believe that the higher incidence of obstructive symptoms in the total fundoplication is caused by some technical aspects during the operative act. RCTs comparing total fundoplication with and without division of short gastric vessels can not show any statistically significant difference in the outcome dysphagia ${ }^{(11)}$. The use of intraesophageal bougies and the confection of a floppy and short valve seems to be effective in reduce dysphagia ${ }^{(8,26)}$, but there are not much trials with methodological quality to confirm theses hypothesis.

Although the more rigorous methodology adopted, our review still have some important limitations. The most of the included studies have a short follow-up and the outcome measures are still unclear. Systematic reviews with meta-analysis are limited by the data included in the RCTs, and the difficulties in the conduction of these kinds of studies, makes that, sometimes, they have poor methology, especially in the surgical area ${ }^{(23)}$. At last, we can not make the meta-analysis in some continuous outcomes, as the post-operative measure of lower esophageal sphincter tonus, because the lack of data.

Another important problem found in sistematic reviews is the publication bias, which is caused by the results of a trial being more likely to be published if a statistically significant benefit of treatment is found. This kind of bias is best avoided by improved literature searching, however, there are some useful diagnostic plots and statistics available that can help detect it, as funnel plots. Without publication bias, this plot should be funnel shaped, with homogeneous distribution of the "positive" and "negative" trials. Unfortunately, this technique requires a large number of trials (10 at least) with a spread of sizes to provide an adequate funnel. In our study, we accepted the possibility to occur publication bias in the outcome "dysphagia", but we do not have enough studies to make a conclusion in the outcome "recurrence of acid reflux". Despite these results, we still think that is always important to perform a strategy to detect the publication bias, because it has important influence in the overall results in systematic reviews and meta-analysis.

With the present review, we can conclude that partial fundoplication can be a good choice in the surgical treatment GERD, with lower rates of obstructive side effects than total fundoplication.

\section{ACKNOWLEDGEMENTS}

The authors thank the Cochrane Center of Brazil, without support this study would not have done.

We like to thank Mr. Regis Andriollo of the Cochrane Center of São Paulo for the technical support. 
Ramos RF, Lustosa SAS, Almeida CAP, Silva CP, Matos D. Tratamento cirúrgico da doença do refluxo gastroesofágico: fundoplicatura total ou parcial? Revisão sistemática da literatura e metanálise. Arq Gastroenterol. 2011;48(4):252-60.

RESUMO - Contexto - Apesar da alta incidência da doença do refluxo gastroesofágico (DRGE) na população em geral, ainda existe muita controvérsia sobre este assunto, especialmente quanto ao tratamento cirúrgico. A decisão de usar fundoplicatura total ou parcial no tratamento da DRGE ainda é um desafio para muitos cirurgiões devido à pouca evidência disponível na literatura. Objetivo - Comparar a fundoplicatura total e as fundoplicaturas parciais no tratamento da DRGE, avaliando a eficácia das duas técnicas operatórias. Método - Foram utilizadas a revisão sistemática da literatura e metanálise de estudos prospectivos e randomizados. Fontes de informação utilizadas: LILACS, MEDLINE, Cochrane Controlled Clinical Trials Database. A metanálise foi realizada utilizando-se o programa de informática da Colaboração Cochrane (Review Manager 5.0.1) e o cálculo dos desfechos foi feito pela razão de chances, com respectivo intervalo de confiança de $95 \%$. Os desfechos estudados foram: disfagia, dificuldade em eructar, plenitude gástrica, recurrência do refluxo ácido, pirose e esofagite. Análise de subgrupo: estudos com seguimento maior que 2 anos. Resultados - Foram selecionados 10 ensaios clínicos, onde 1003 doentes foram estudados, sendo 502 alocados para o grupo fundoplicatura total e 501 locados para o grupo fundoplicatura parcial. Os desfechos contínuos não puderam ser calculados em razão da falta de dados. Somente os desfechos disfagia e dificuldade em eructar tiveram resultados estatisticamente significantes $(P<0.0001)$ a favor da fundoplicatura parcial. Conclusão - A fundoplicatura parcial está relacionada com a menor incidência de eventos obstrutivos pós-operatórios.

DESCRITORES - Refluxo gastroesofágico, cirurgia. Fundoplicatura. Revisão. Metanálise.

\section{REFERENCES}

1. Baigrie RJ, Cullis SN, Ndhluni AJ, Cariem A. Randomized double-blind trial of laparoscopic Nissen fundoplication versus anterior partial fundoplication. Br J Surg. 2005;92:819-23.

2. Bell RC, Hanna P, Mills MR, Bowrey D. Patterns of success and failure with laparoscopic Toupet fundoplication. Surg Endosc. 1999;13:1189-94.

3. Booth MI, Stratford J, Jones L, Dehn TC. Randomized clinical trial of laparoscopic total (Nissen) versus posterior partial (Toupet) fundoplication for gastro-oesophageal reflux disease based on preoperative oesophageal manometry. Br J Surg. 2008;95:57-63.

4. Cai W, Watson DI, Lally CJ, Davitt PG, Game PA, Jamieson GG. Ten-year clinical outcome of a prospective randomized clinical trial of laparoscopic Nissen versus anterior 180 (degrees) partial fundoplication. Br J Surg. 2008;95:1501-5.

5. Catarci M, Gentileschi P, Papi C, Carrara A, Marrese R, Gaspari AL, Grassi GB. Evidence-based appraisal of antireflux fundoplication. Ann Surg. 2004;239:325-37.

6. Chrysos E, Athanasakis E, Pechlivanides, Tzortziniz A, Mantides A, Xynos E. The effect of total and anterior partial fundoplication on antireflux mechanisms of the gastroesophageal junction. Am J Surg. 2004;188:39-44.

7. Civello IM, Brisinda G, Sganga G, De Fazio S, Maria G, Crucitti Fl. Modified Hill operation vs. Nissen fundoplication in the surgical treatment of gastroesophageal reflux disease. Hepatogastroenterology. 1997;44:380-6.

8. Davis RE, Awad ZT, Filipi CJ. Technical factors in the creation of a "floppy" Nissen fundoplication. Am J Surg. 2004;187:724-7.

9. DeMeester R, Johnson LF, Kent AH. Evaluation of current operations for the prevention of gastro esophageal reflux. Ann Surg. 1974;180:511-23.

10. Esposito C, Montupet P, van der Zee D, Settimi A, Paye-Jaouen A, Centonze A, Bax NK. Long-term outcomes of laparoscopic Nissen, Toupet and Thal antireflux procedures for neurologically normal children with gastroesophageal reflux disease. Surg Endosc. 2006;20:855-8.

11. Farah JFM, Del Grande JC, Goldenberg A, Martinez JC, Lupinacci, RA, Matone J. Randomized trial of total fundoplication and fundal mobilization with and without division of short gastric vessels: a short-term clinical evaluation. Acta Cir Bras. 2007;22:422-9.

12. Fibbe C, Layer P, Keller J, Strate U, Emmermann A, Zornig C. Esophageal motility in reflux disease before and after fundoplication: a prospective, randomized, clinical and manometric study. Gastroenterology. 2001;121:5-14.

13. Fuchs K-H, Heimbucher J, Freys SM, Thiede A. Management of gastroesophageal reflux disease 1995. Tailored concept of anti-reflux operations. Dis Esophagus. 1994;7:250-4.

14. Guérin E, Bétroune K, Closset J, Mehdi A, Lefèbvre JC, Houben JJ, Gelin M, Vaneukem P, El Nakadi I. Nissen versus Toupet fundoplication: results of a randomized and multicenter trial. Surg Endosc. 2007;21:1985-90.

15. Hagedorn C, Lönroth H, Rydberg L, Ruth M, Lundell L. Long-term efficacy of total (Nissen-Rossetti) and posterior partial (Toupet) fundoplication: results of a randomized clinical trial. J Gastrointest Surg. 2002;6:540-5.
16. Khan MA, Smythe A, Globe J, Stoddard CJ, Ackroyd R. Randomized controlled trial of laparoscopic Nissen versus Lind fundoplication for gastro-oesophageal reflux disease. Scand J Gastroenterol. 2009;44:269-75.

17. Klapow JC, Wilcox CM, Mallinger AP, Marks R, Heudebert GR, Centor RM, Lawrence W, Richter J. Characterization of long-term outcomes after Toupet fundoplication: symptoms, medication use, and health status. J Clin Gastroenterol. 2002;34:509-15.

18. Laws H, Clements HR, Swillie, CM. A randomized, prospective comparison of the Nissen fundoplication versus Toupet fundoplication for gastroesophageal reflux disease. Ann Surg. 1997;225:647-53.

19. Lind JF, Burns CM, MacDougall JT. Physiological repair for hiatus hernia manometric study. AMA Arch Surg. 1965;91:233-7.

20. Ludemann R, Watson DI, Jamieson GG, Game PA, Devitt PG. Five-year follow-up of a randomized clinical trial of laparoscopic total versus anterior 180 degrees fundoplication. Br J Surg. 2005;92:240-3.

21. Lundell L, Abrahamsson H, Ruth M, Sandberg N, Olbe LC. Lower esophagea sphincter characteristics and esophageal acid exposure following partial or 360 degrees fundoplication: results of a prospective, randomized clinical study. World J Surg. 1991;15:115-21.

22. Lundell L, Miettinen P, Myrvold HE, Pedersen SA, Liedman B, Hatlebakk JG, Julkonen R, Levander K, Carlsson J, Lamm M, Wiklund I. Continued (5-year) follow-up of a randomized clinical study comparing antireflux surgery and omeprazole in gastroesophageal reflux disease. J Am Coll Surg. 2001;192:172-81.

23. McLeod RS, Wright JG, Solomon MJ, Hu X, Walters BC, Lossing A. Randomized controlled trials in surgery: issues and problems. Surgery. 1996;119:483-6.

24. Mickevicius A, Endzinas Z, Kiudelis M, Jonaitis L, Kupcinskas L, Maleckas A, Pundzius J. Influence of wrap length on the effectiveness of Nissen and Toupet fundoplication: a prospective randomized study. Surg Endosc. 2008;22:2269-76.

25. Nissen R. Gastropexy as the lone procedure in the surgical repair of hiatus hernia. Am J Surg. 1956;92:389-92.

26. Patterson EJ, Herron DM, Hansen PD, Ramzi N, Standage BA, Swanström LL. Effect of an esophageal bougie on the incidence of dysphagia following Nissen fundoplication: a prospective, blinded randomized clinical trial. Arch Surg. 2000;135:1055-62.

27. Revicki DA, Wood M, Maton PN, Sorensen S. The impact of gastroesophageal reflux disease on health related quality of life. Am J Med. 1998;104:252-8.

28. Rydberg L, Ruth M, Abrahamsson H, Lundell L. Tailoring anti-reflux surgery: a randomized clinical trial. World J Surg. 1999;23:612-8.

29. Sandler RS, Everhart JE, Donowitz M, Adams E, Cronin K, Goodman C, Gemmen E, Shah S, Avdic A, Rubin R. The burden of selective of digestive diseases in the United States. Gastroenterology. 2002;122:1500-11.

30. Segol P, Hay JM, Pottier D. [Surgical treatment of gastroesophageal: which operation to choose: Nissen, Toupet or Lortat-Jacob? A multicenter randomized trial]. Gastroenterol Clin Biol. 1989;13:873-9.

31. Spence GM, Watson DI, Jamiesion GG, Lally CJ, Devitt PG. Single center prospective randomized trial of laparoscopic Nissen versus anterior 90 degrees fundoplication. J Gastrointest Surg. 2006;10:698-705. 
32. Strate U, Emmerman A, Fibbe C, Layer P, Zornig C. Laparoscopic fundoplication: Nissen versus Toupet two-year outcome of a prospective randomized study of 200 patients regarding preoperative esophageal motility. Surg Endosc. 2008;22:21-30.

33. Thor KBA, Silander T. A long-term randomized prospective trial of Nissen procedure versus a modified Toupet technique. Ann Surg.1989;210:719-24.

34. Toupet A. [Technique of esophago-gastroplasty with phrenogastropexy used in radical treatment of hiatal hernias as supplement of Heller's operation in cardioespasms]. Mem Acad Chir (Paris). 1963;89:384-9.

35. Varin O, Velstra B, De Sutter S, Ceelen W. Total vs. partial fundoplication in the treatment of gastroesophageal reflux disease. A meta-analysis. Arch Surg. 2009; $144: 273-8$

36. Walker SJ, Holt S, Sanderson CJ, Stoddard CJ. Comparison of Nissen total and Lind partial transabdominal fundoplication in the treatment of gastrooesophageal reflux. Br J Surg. 1992;79:410-4.
37. Watson DI, Jamieson GG, Pike GK, Davies N, Richardson M, Devitt PG Prospective randomized double-blind trial between laparoscopic Nissen fundoplication and anterior partial fundoplication. Br J Surg. 1999;86:123-30.

38. Watson DI, Jamieson GG, Lally C, Archer S, Bessell JR, Booth M, Cade R, Cullingford G, Devitt PG, Fletcher DR, Hurley J, Kiroff G, Martin Cj, Martin IJ, Nathanson LK, Windsor JA; International Society for diseases of Esophagus - Australian Section. Multicenter, prospective, double-blind randomized trial of laparoscopic Nissen vs anterior 90 degrees partial fundoplication. Br J Surg. 2004;139:1160-7.

39. Zornig C, Strate U, Fibbe C, Emmermann A, Layer P. Nissen vs. Toupet laparoscopic fundoplication. Surg Endosc. 2002;16:758-66.

Received 7/4/2011. Accepted 9/6/2011. 